\title{
Metabolism of dehydroretinyl ester in white leghorn chicks
}

\author{
By BHABESH C. GOSWAMI AND ARUN B. BARUA*† \\ Department of Chemistry, University of Gauhati, Gauhati-781014, India
}

(Received 10 June 1985 - Accepted 8 October 1985)

\begin{abstract}
1. The metabolism of dehydroretinyl ester has been studied in vitamin-A-deficient white leghorn chicks. Dehydroretinyl ester was metabolized to 3-hydroxyretinol diester, 3-hydroxyanhydroretinol and rehydrovitamin $A_{2}$ which were isolated from the intestines and livers of chicks.

2. The metabolism of 3-hydroxyretinol diester and 3-hydroxyanhydroretinol, which were immediate metabolites of dehydroretinol, was studied in chicks.

3. Retinol was not detected in these experiments.
\end{abstract}

Dehydroretinol, first observed in fish-liver oil, is mainly found in freshwater fish, but occurs to a small extent in marine fish and certain amphibia. Dehydroretinol and its analogues have about half the activity of the corresponding retinol compounds (Shantz \& Brinkmann, 1950; Sundaresan \& Cama, 1961). Transformation of retinol to dehydroretinol has been reported by many workers (Naito \& Wilt, 1962; Braekkan et al. 1969; Lambertson \& Braekkan, 1969), but they concluded that the animal systems studied possess a dehydrogenation system of limited capacity. Yoshikami et al. (1969) have reported the conversion of dehydroretinol to retinol in the eyes of vitamin-A-deficient rats. However, Goswami \& Barua (1981) have shown that freshwater fish cannot convert dehydroretinol to retinol or vice versa. Howell et al. (1967) have established that dehydroretinol helps reproduction in female rats. Recently Wilson (1984) has shown that dehydroretinol restores spermatogenesis in vitamin-A-deficient rats with no detectable conversion to retinol. A recent study on the metabolism of cryptoxanthin in retinol-rich freshwater fish has shown it to be similar to that in mammalian species but different in dehydroretinol-rich freshwater fish where cryptoxanthin is converted to 3-hydroxyretinol and dehydroretinol (Goswami, 1984). Studies on the conversion of lutein and cryptoxanthin into both dehydroretinol and 3-hydroxyretinol in freshwater fish (Barua \& Das, 1975; Goswami, 1984) have led to the isolation and characterization of a number of new analogues of dehydroretinol and therefore we considered it necessary to reinvestigate the metabolism of dehydroretinol in animals other than freshwater fish. The present paper describes the metabolism of dehydroretinyl ester and two analogues in vitamin-A-deficient and normal white leghorn chicks.

MATERIALS AND METHODS

Sources and methods of purification of all the solvents were as described previously (Barua et al. 1979). Light petroleum used throughout the present investigation had a boiling point of $40-60^{\circ}$.

White leghorn chicks (1-d-old) obtained from the State Poultry Farm at Birubari, Gauhati, were used throughout the study. The chicks were maintained on the vitaminA-deficient diet of Joshi et al. (1973). The chicks reached weight-plateau stage within 15-20 d. The chicks were used when they reached the acute deficiency stage, i.e. about 4-6 d after USA.

* Present address: Department of Biochemistry \& Biophysics, Iowa State University, Ames, Iowa 50011,

$\dagger$ For reprints. 
weight-plateau stage. A few chicks were maintained on a vitamin-A-deficient diet supplemented with $280 \mu \mathrm{g}$ retinyl acetate/chick per week. These chicks were termed normal chicks.

A Beckman DK-2 spectrophotometer was used to record the u.v. and visible absorption spectra. Column chromatography and thin-layer chromatography (tlc) were carried out as described previously (Barua et al. 1977, 1979). The concentrations of all vitamin A compounds were calculated from the absorption values used by Barua et al. (1977).

\section{Chromatography of liver oil of Wallago attu}

The oil was extracted from the livers of freshwater fish, W. attu (Barua et al. 1977) and was separated by chromatography on a column $(30 \mathrm{~mm} \times 180 \mathrm{~mm})$ of $60 \mathrm{~g}$ alumina with $50 \mathrm{ml}$ water $/ \mathrm{kg}$. The column was developed with light petroleum containing various proportions of diethyl ether $(10-350 \mathrm{ml} / 1)$.

\section{Isolation of dehydroretinyl ester}

The fractions eluted with light petroleum were pooled, concentrated and rechromatographed twice more using a column $(10 \mathrm{~mm} \times 100 \mathrm{~mm})$ of $10 \mathrm{~g}$ alumina $(50 \mathrm{ml}$ water $/ \mathrm{kg})$. Thus purified, the dehydroretinyl ester was further purified by tlc on silica-gel plates $(0.25 \mathrm{~mm}$ thickness). The purified compound $\left(R_{\mathrm{f}} 0 \cdot 76\right.$; solvent system: acetone-light petroleum $50: 100, \mathrm{v} / \mathrm{v})$ showed absorption maxima $\left(\lambda_{\max }\right)$ at $350,286,276 \mathrm{~nm}$ in light petroleum.

\section{Isolation of 3-hydroxyretinol diester}

The liver-oil fraction eluted with light petroleum containing 10-20 ml diethyl ether/1 was separated by chromatography on a column $(10 \mathrm{~mm} \times 100 \mathrm{~mm}$ ) of $10 \mathrm{~g}$ alumina (with $50 \mathrm{ml}$ water $/ \mathrm{kg}$ ) and was further purified by tlc on silica gel plates. The purified diester of 3-hydroxyretinol ( $R_{\mathrm{f}} 0 \cdot 68$; solvent system: acetone-light petroleum 10:100, v/v) had $\lambda_{\max }$ at $328 \mathrm{~nm}$ in light petroleum.

\section{Isolation of 3-hydroxyanhydroretinol and rehydrovitamin $A_{2}$}

The chromatographic fractions eluted with light petroleum containing $80-100 \mathrm{ml}$ diethyl ether $/ 1$ and $150-200 \mathrm{ml}$ diethyl ether $/ 1$ were pooled separately and purified by tlc. The following solvent systems were used for purification: ethyl acetate-cyclohexane $(20: 100$, $\mathrm{v} / \mathrm{v})$ for 3-hydroxyanhydroretinol, acetone-light petroleum $(20: 100, \mathrm{v} / \mathrm{v})$ for rehydrovitamin $\mathrm{A}_{2}$.

\section{Method of administration}

The estimated amounts of vitamin A compounds were dissolved in $0.4 \mathrm{ml}$ groundnut oil containing $5 \mathrm{~g} \alpha$-tocopheryl acetate/1. The oil was administered directly to the chicks orally using a calibrated $1 \mathrm{ml}$ syringe with the help of polyethylene tubing fixed to the needle.

\section{Administration of dehydroretinyl ester to vitamin-A-deficient chicks}

The vitamin-A-deficient chicks were administered with amounts of dehydroretinyl ester for a number of days as shown in Table 1 . The chicks were killed $24 \mathrm{~h}$ after the last dose and the metabolites were extracted from the livers with light petroleum after grinding the livers with acid-washed sea-sand and anhydrous sodium sulphate. The extraction was repeated until a fresh extract was insensitive to antimony trichloride. The pooled extract was concentrated by rotary evaporation under reduced pressure. The crude oil was dissolved in $2 \mathrm{ml}$ light petroleum and separated by chromatography on a column $(10 \mathrm{~mm} \times 100 \mathrm{~mm}$ ) of $10 \mathrm{~g}$ alumina (with $50 \mathrm{~g}$ water $/ \mathrm{kg}$ ). The compounds were eluted with light petroleum and light petroleum containing increasing proportions $(10-350 \mathrm{ml} / \mathrm{l})$ of diethyl ether. 
Table 1. Absorption and storage of dehydroretinyl ester in vitamin-A-deficient chicks

\begin{tabular}{|c|c|c|c|c|c|c|}
\hline \multirow[b]{2}{*}{$\begin{array}{l}\text { Expt } \\
\text { no. }\end{array}$} & \multirow[b]{2}{*}{$\begin{array}{l}\text { No. of } \\
\text { chicks }\end{array}$} & \multirow[b]{2}{*}{$\begin{array}{c}\text { Amount of } \\
\text { dehydroretinyl } \\
\text { ester administered } \\
(\mu \mathrm{g} / \text { chick per } \mathrm{d})\end{array}$} & \multirow[b]{2}{*}{$\begin{array}{l}\text { Period of } \\
\text { admini- } \\
\text { stration (d) }\end{array}$} & \multicolumn{3}{|c|}{$\begin{array}{l}\text { Analysis of liver extract } \\
(\mu \mathrm{g} / \text { liver })\end{array}$} \\
\hline & & & & $\begin{array}{l}\text { Dehydro- } \\
\text { retinyl } \\
\text { ester }\end{array}$ & $\begin{array}{l}\text { 3-Hydroxy- } \\
\text { retinol } \\
\text { diester }\end{array}$ & $\begin{array}{c}\text { Rehydro- } \\
\text { vitamin } \\
\mathrm{A}_{2}\end{array}$ \\
\hline 1 & 1 & 170 & 10 & - & - & - \\
\hline 2 & 1 & 170 & 18 & $8 \cdot 2$ & - & - \\
\hline 3 & 2 & 1000 & 2 & - & - & - \\
\hline 4 & 1 & 1000 & 6 & $5 \cdot 3$ & $2 \cdot 8$ & - \\
\hline 5 & 2 & 1000 & 10 & 15.8 & $8 \cdot 3$ & $26 \cdot 6$ \\
\hline 6 & 3 & 340 & 14 & $144 \cdot 0$ & - & $29 \cdot 5$ \\
\hline 7 & 1 & 2000 & 1 & $41 \cdot 0$ & $12 \cdot 1$ & 3.0 \\
\hline
\end{tabular}

Table 2. Metabolism and absorption of dehydroretinyl ester in vitamin-A-deficient chicks

\begin{tabular}{ccccccc}
\hline \multirow{2}{*}{$\begin{array}{c}\text { Period } \\
\text { between } \\
\text { dosing and } \\
\text { death (h) }\end{array}$} & $\begin{array}{c}\text { No. of } \\
\text { chicks }\end{array}$ & $\begin{array}{c}\text { Dehydro- } \\
\text { retinyl } \\
\text { ester }\end{array}$ & $\begin{array}{c}\text { 3-Hydroxy- } \\
\text { retinol } \\
\text { diester }\end{array}$ & $\begin{array}{c}\text { 3-Hydroxy- } \\
\text { anhydro- } \\
\text { retinol }\end{array}$ & $\begin{array}{c}\text { Rehydro- } \\
\text { vitamin } \\
\text { A }_{2}\end{array}$ & $\begin{array}{c}\text { Dehydro- } \\
\text { retinol }\end{array}$ \\
\cline { 3 - 7 } & 2 & 3526.5 & - & - & - & - \\
2 & 2 & 1621.9 & 146.6 & - & 149 & - \\
3 & 2 & 1185.0 & 341.6 & 21.5 & 218.5 & $9 \cdot 5$ \\
4 & 2 & 776.4 & 300.4 & - & 183 & $110 \cdot 7$ \\
5 & 2 & 505.0 & 72.2 & 14.0 & 120 & - \\
7 & 2 & 518.5 & 36.6 & - & 125.8 & - \\
\hline
\end{tabular}

Metabolism and absorption of a single dose of dehydroretinyl ester

In this experiment, each of twelve vitamin-A-deficient chicks were given one single dose of $3 \mathrm{mg}$ dehydroretinyl ester dissolved in $0.4 \mathrm{ml}$ groundnut oil containing $5 \mathrm{~g} \alpha$-tocopheryl acetate $/ 1$. Groups of two chicks were killed after different time intervals as indicated in Table 2 . The intestinal mucosa was removed, extracted and separated by chromatography on a column $(10 \mathrm{~mm} \times 100 \mathrm{~mm}$ ) of $10 \mathrm{~g}$ alumina (with $50 \mathrm{ml}$ water $/ \mathrm{kg}$ ) and different fractions were characterized.

Metabolism of dehydroretinyl ester, 3-dehydroxyretinol diester and 3-hydroxyanhydroretinol in normal chicks

Two normal chicks ( 1 month old), after receiving the vitamin-A-deficient diet for 1 week and then starved for $48 \mathrm{~h}$, were administered with $3 \mathrm{mg}$ dehydroretinyl ester dissolved in $0.4 \mathrm{ml}$ groundnut oil containing $5 \mathrm{~g} \alpha$-tocopheryl acetate/l. One chick was killed after $2 \mathrm{~h}$, while the other was killed after $4 \mathrm{~h}$ and intestinal mucosa extracts were separated and characterized (Table 3). In a similar way, two groups of normal chicks received 3-hydroxyretinol diester and 3-hydroxyanhydroretinol and the metabolites were separated and characterized (Table 3).

Analysis of the liver of a vitamin-A-deficient chick given 3-hydroxyretinol diester In this experiment, one vitamin-A-deficient chick was administered with $2 \mathrm{mg} 3$-hydroxyretinol diester dissolved in $0.4 \mathrm{ml}$ groundnut oil containing $5 \mathrm{~g} \alpha$-tocopheryl acetate/l per $\mathrm{d}$ for $8 \mathrm{~d}$. The chick was killed $24 \mathrm{~h}$ after the last dose and the liver extracted immediately. 
Analysis of the liver of a vitamin-A-deficient chick given 3-hydroxyanhydroretinol

In this experiment also, one vitamin-A-deficient chick was administered with $1 \mathrm{mg}$ 3-hydroxyanhydroretinol dissolved in $0.4 \mathrm{ml}$ groundnut oil containing $5 \mathrm{~g} \alpha$-tocopheryl acetate $/ 1$ per $\mathrm{d}$. After supplementation for $5 \mathrm{~d}$ the chick was killed $24 \mathrm{~h}$ after the last dose and the liver analysed.

\section{RESULTS}

Analysis of livers of vitamin-A-deficient chicks given different doses of dehydroretinyl ester The fraction eluted from the alumina column with light petroleum was characterized as dehydroretinyl ester from its u.v.-absorption spectra $\left(\lambda_{\max } 350,286,276 \mathrm{~nm}\right), \mathrm{SbCl}_{3}$-colour maximum $\left(\lambda_{\max } 695 \mathrm{~nm}\right)$ and co-chromatography with a sample of dehydroretinyl ester isolated from the livers of $W$. attu. Both the compounds had a $R_{\mathrm{f}}$ value of 0.76 using a solvent system of $50 \mathrm{ml}$ acetone/ 1 light petroleum.

The fraction eluted with light petroleum containing $10-20 \mathrm{ml}$ diethyl ether $/ 1$ was identified as 3-hydroxyretinol ester, as judged from the u.v.-absorption spectrum $\left(\lambda_{\max }\right.$ $328 \mathrm{~nm})$ and $\mathrm{SbCl}_{3}$-colour maximum $\left(\lambda_{\max } 675 \mathrm{~nm}\right)$. The metabolite was subjected to co-chromatography $\left(R_{\mathrm{p}} 0.68\right.$; solvent system: acetone-light petroleum 10:100, v/v) with a known sample of 3-hydroxyretinol diester isolated from livers of $W$. attu.

A compound was also eluted with light petroleum containing 150-200 ml diethyl ether/1 which had $\lambda_{\max }$ at $365,348,332, \sim 312 \mathrm{~nm}$. This gave $\mathrm{SbCl}_{3}$-colour maximum $\left(\lambda_{\max }\right.$ $640 \mathrm{~nm})$ and its chromatographic behaviour $\left(R_{\mathrm{f}} 0.48\right.$; solvent system: acetone-light petroleum 20:100, v/v) was identical to that of rehydrovitamin $A_{2}$ isolated from livers of $W$. attu. Therefore this compound was indistinguishable from rehydrovitamin $A_{2}$.

\section{Metabolism and absorption of a single dose of dehydroretinyl ester}

The first, second and fourth fractions from the alumina column of the intestinal extract were characterized as dehydroretinyl ester, 3-hydroxyretinol diester and rehydrovitamin $\mathrm{A}_{2}$ (Table 2) respectively as described previously. The third fraction eluted with light petroleum containing $80-100 \mathrm{ml}$ diethyl ether $/ 1$ was characterized as 3-hydroxyanhydroretinol from its u.v.-absorption $\left(\lambda_{\max } 390,369,350, \sim 333 \mathrm{~nm}\right), \mathrm{SbCl}_{3}$-colour maximum at $690 \mathrm{~nm}$, chromatographic behaviour $\left(R_{\mathrm{f}} 0 \cdot 21\right.$; solvent system: acetone-light petroleum $\left.30: 100, \mathrm{v} / \mathrm{v}\right)$ and brown fluorescence under u.v. lamp. The fifth fraction, eluted with light petroleum containing $250-300 \mathrm{ml}$ diethyl ether/l, was characterized as dehydroretinol from its $\lambda_{\max }$ at $350,286,276 \mathrm{~nm}$ and $\mathrm{SbCl}_{3}$-colour maximum at $695 \mathrm{~nm}$ and chromatographic behaviour $\left(R_{\mathrm{f}} 0 \cdot 53\right.$; solvent system: acetone-light petroleum $\left.30: 100, \mathrm{v} / \mathrm{v}\right)$.

\section{Metabolism of dehydroretinyl ester, 3-hydroxyretinol diester and 3-hydroxyanhydroretinol in normal chicks}

The compounds that were isolated from the intestines of chicks receiving dehydroretinyl ester and 3-hydroxyretinol diester are shown in Table 3.

The metabolite isolated from the intestines of chicks administered with 3-hydroxyanhydroretinol was found to contain three fractions. The first fraction, eluted with light petroleum, had an absorption spectrum with $\lambda_{\max }$ at $390,369,350, \sim 333 \mathrm{~nm}$ and $\mathrm{SbCl}_{3}$-colour maximum at $690 \mathrm{~nm}$. The fraction $\left(R_{\mathrm{f}} 0.92\right.$; solvent system:acetone-light petroleum $\left.20: 100, \mathrm{v} / \mathrm{v}\right)$ was saponified with potassium hydroxide $(100 \mathrm{~g} / 1)$ at $50^{\circ}$ for $1 \mathrm{~h}$. It was then extracted with diethyl ether, washed several times with water to remove alkali, dried with anhydrous sodium sulphate and concentrated by rotary evaporation. The saponified product moved to the same distance as that of 3-hydroxyanhydroretinol $\left(R_{\mathrm{f}} 0.68\right.$; solvent system: acetone-light petroleum $20: 100, v / v)$. In addition, the fraction showed brown fluorescence 
Table 4. Absorption and storage of 3-hydroxyretinol diester and 3-hydroxyanhydroretinol

\begin{tabular}{|c|c|c|c|c|c|}
\hline \multirow[b]{2}{*}{ Compound } & \multirow[b]{2}{*}{$\begin{array}{l}\text { No. of } \\
\text { chicks }\end{array}$} & \multirow{2}{*}{$\begin{array}{l}\text { Amount } \\
\text { administered } \\
(\mu \mathrm{g} / \text { chick } \\
\text { per d) }\end{array}$} & \multirow[b]{2}{*}{$\begin{array}{l}\text { Period of } \\
\text { admini- } \\
\text { stration (d) }\end{array}$} & \multicolumn{2}{|c|}{$\begin{array}{l}\text { Liver content of } \\
\text { vitamin } \mathrm{A} \text { derivatives } \\
(\mu \mathrm{g} / \text { liver })\end{array}$} \\
\hline & & & & $\begin{array}{l}\text { 3-Hydroxy- } \\
\text { retinol } \\
\text { diester }\end{array}$ & $\begin{array}{l}\text { Rehydro- } \\
\text { vitamin } A_{2}\end{array}$ \\
\hline 3-Hydroxyretinol diester & 1 & 2000 & 8 & $11 \cdot 1$ & - \\
\hline 3-Hydroxyanhydroretinol & 1 & 1000 & 5 & - & $3 \cdot 3$ \\
\hline
\end{tabular}

under u.v. lamp. The previously-described factors all confirmed the fraction as 3hydroxyanhydroretinol ester. The second and third fractions were of the unconverted 3-hydroxyanhydroretinol and rehydrovitamin $A_{2}$ (Table 3) respectively, characterized as described previously.

\section{Analysis of the livers of vitamin-A-deficient chicks given 3-hydroxyretinol diester or 3-hydroxyanhydroretinol}

The liver extract of the vitamin-A-deficient chick receiving 3-hydroxyretinol diester showed only the presence of 3-hydroxyretinol diester (Table 4), while the chick receiving 3hydroxyanhydroretinol showed only the presence of rehydrovitamin $A_{2}$ (Table 4) characterized as described previously.

\section{DISCUSSION}

There are several reports on the interconversion of retinol and dehydroretinol. However, studies in this laboratory on the conversion of retinol to dehydroretinol in freshwater fish indicated that the freshwater fish Saccobranchus fossilis was unable to convert any retinol to dehydroretinol. Similarly, no indication was obtained of the conversion of dehydroretinol to retinol (Goswami \& Barua, 1981). The present study on the metabolism of dehydroretinol in both normal and vitamin-A-deficient chicks indicates that dehydroretinyl esters are metabolized to 3-hydroxyretinol diester, 3-hydroxyanhydroretinol and rehydrovitamin $A_{2}$. Of particular interest was the appearance of rehydrovitamin $A_{2}$. We therefore attempted to study the origin of rehydrovitamin $\mathrm{A}_{2}$ in chicks.

The structure of rehydrovitamin $A_{2}$ is not known, but a possible structure proposed by Balasundaram et al. (1958) is shown in Fig. 1. It is possible that rehydrovitamin $A_{2}$ arises from 3-hydroxyretinol. 3-Hydroxyretinol possesses a biological activity of $11.7 \%$ of that of all-trans-retinyl acetate determined by curative growth assay (Goswami et al. 1980). Experiments on the absorption of 3-hydroxyretinol diester by rats indicated that it was absorbed as such after hydrolysis to 3-hydroxyretinol and deposited in the liver again as the diester without any change in structure (Goswami et al. 1980). The metabolism of 3-hydroxyretinol diester in white leghorn chicks in the present study was found to be exactly similar to the metabolism of 3-hydroxyretinol in rats and no other metabolite could be isolated from the intestine or the liver. It was therefore concluded that rehydrovitamin $\mathrm{A}_{2}$ does not arise from 3-hydroxyretinol. However, 3-hydroxyretinol is converted into 3-hydroxyanhydroretinol in freshwater fish (Barua et al. 1979).

Rehydrovitamin $\mathrm{A}_{2}$ might have arisen from 3-hydroxyanhydroretinol. Studies on the metabolism of 3-hydroxyanhydroretinol in the chick indicated that 3-hydroxyanhydroretinol was metabolized to 3-hydroxyanhydroretinol ester and rehydrovitamin $\mathrm{A}_{2}$ in the intestine 


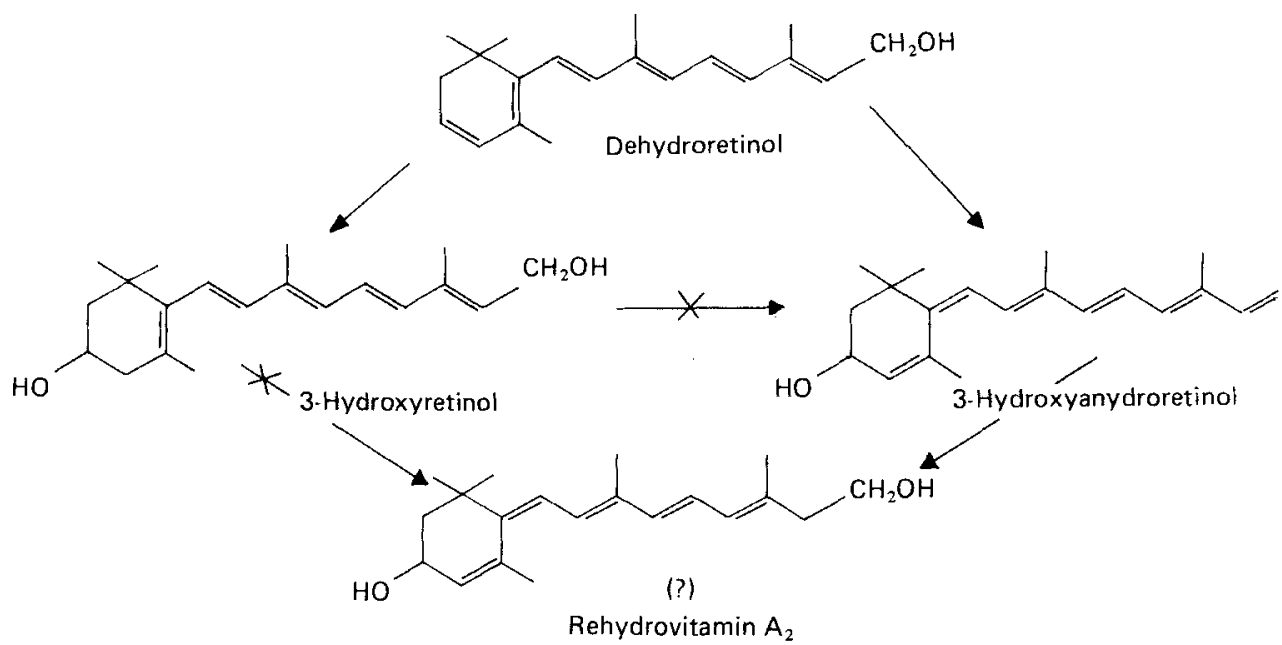

Fig. 1. Metabolic pathway of dehydroretinol in chicks.

of vitamin-A-deficient chicks. However, the analysis of the liver of vitamin-A-deficient chicks administered with 3-hydroxyanhydroretinol showed only the presence of rehydrovitamin $A_{2}$ and no 3-hydroxyanhydroretinol or its ester.

We could not detect retinol or retinyl ester in these experiments but we succeeded in isolating 3-hydroxyretinol, the absorption spectrum of which is exactly similar to that of retinol $\left(\lambda_{\max } 325 \mathrm{~nm}\right)$. The question therefore arises from previous reports on whether the appearance of retinol after administration of dehydroretinol was due to retinol itself or due to 3-hydroxyretinol.

In conclusion, the metabolic pathway of dehydroretinol in chicks can possibly be represented by the scheme presented in Fig. 1.

The authors wish to thank Dr G. A. J. Pitt and Dr S. R. Das for some useful discussions. Financial assistance from the University Grants Commission, New Delhi to B.C.G. is gratefully acknowledged.

\section{REFERENCES}

Balasundaram, S., Bamji, M. S., Cama, H. R., Sundaresan, P. R. \& Verma, T. N. R. (1958). Journal of Biological Chemistry 233, 827-832.

Barua, A. B. \& Das, R. C. (1975). British Journal of Nutrition 33, 319-327.

Barua, A. B., Das, R. C. \& Verma, K. (1977). Biochemical Journal 168, 557-564.

Barua, A. B., Singh, H. T. \& Das, R. C. (1973). British Journal of Nutrition 30, 1-12.

Barua, A. B., Verma, K. \& Das, S. R. (1979). Biochemical Journal 177, 791-799.

Braekkan, O. R., Ingebrigtsen, O. \& Myklestad, H. (1969). International Journal for Vitamin Research 39, $123-130$.

Goswami, U. C. (1984). British Journal of Nutrition 52, 575-581.

Goswami, B. C. \& Barua, A. B. (1981). Indian Journal of Biochemistry and Biophysics 18, 159-160.

Goswami, B. C., Barua, A. B. \& Sastry, P. S. (1980). Indian Journal of Biochemistry and Biophysics 17, $457-461$.

Howell, J. M., Thompson, J. N. \& Pitt, G. A. J. (1967). British Journal of Nutrition 21, 373-376.

Joshi, P. S., Mathur, S. N., Murthy, S. K. \& Ganguly, J. (1973). Biochemical Journal 136, 757-761.

Lambertson, G. \& Braekkan, O. R. (1969). Acta Chemica Scandinavica 23, 1063-1066.

Naito, K. \& Wilt, F. H. (1962). Journal of Biological Chemistry 237, 3060-3064.

Shantz, E. M. \& Brinkmann, J. H. (1950). Journal of Biological Chemistry 183, 467-471.

Sundaresan, P. R. \& Cama, H. R. (1961). British Journal of Nutrition 15, 225-230.

Wilson, T. C. M. (1984). The metabolism of dehydroretinol in the rat. PhD Thesis, University of Liverpool.

Yoshikami, S., Pearlman, J. T. \& Crescitelli, F. (1969). Vision Research 9, 633-646. 